\title{
Exploring Solutions and the Role of GDS Technology in Crossing the Current Pandemic Context in Tourism
}

\author{
https://doi.org/10.2478/ejthr-2021-0009 \\ received December 14, 2020; accepted April 26, 2021
}

\begin{abstract}
In the current pandemic context, tourists increasingly need to receive assurances from the tourism and hospitality industry that their safety and health will not be endangered during their trip or their stay. Tourists increasingly prefer to plan their own trips and information technology is playing a very important role in the hotel and tourism industry. This study uses strategic management methods and comparative analysis to formulate strategies, measures, and solutions to maintain the safety and the health of tourists at the level of the tourism and hospitality industry. The aim of the paper is to provide solutions for the tourism industry in the current context of the COVID-19 pandemic, through a strategic managerial approach and by involving information technology and global distribution systems (GDSs) as a decision supporting tool. The results of the study are useful for small and medium enterprises to act efficiently in this pandemic context, but are also useful for GDS providers to reflect on possible improvements in system functionality to implement solutions and to support the decisions of tourists.
\end{abstract}

Keywords: Technology; tourism; GDS; Innovative solutions; Pandemic context.

\section{Introduction}

COVID-19 has changed the world and people's perceptions of travel. It has had a strong impact on the tourism and hospitality industry (Chandrasekaran \& Dhanalakshmi, 2020; Chang et al., 2020a; Kumar, 2020). From an economic point of view, the impact of COVID-19 has so far been more devastating than any other crisis in recent history (Hall et al., 2020). The crisis has raised new questions about how the tourism industry can respond to and recover from this crisis (Gretzel et al., 2020). Finding solutions and answers to such questions becomes a necessity for tourism stakeholders, including research communities (Gössling et al., 2020; Jamal \& Budke, 2020). This pandemic should be seen as an 'eye opener' for stakeholders who need to prepare and develop strong response strategies and find solutions (Khan, 2020). Technology plays a central role in all this, and it is the basis for solutions to combat COVID-19 and the reopening of tourism and the economy (Sigala, 2020).

Moreover, it is necessary to understand the effects of the coronavirus pandemic on the tourist psyche. The psychological concepts of ethnocentrism, xenophobia, and perceptions of agglomeration refer to the perceived infectivity of COVID-19 (Kock et al., 2020), so solutions are needed to give tourists a sense of security that reduces perceptions of the risk of travel.

In the current pandemic context, tourists increasingly need to receive assurances from the tourism and hospitality industry that their safety and health will not be endangered during their trip or during their stay in accommodations and catering units. The hospitality and tourism industry has a valuable role to play in developing a strong health communication strategy (Jamal \& Budke, 2020). Technology is seen as a panacea for our COVID-19-drivenneeds to normalise surveillance and to ensure the health and safety of tourists (Sigala, 2020).

Nowadays, tourists prefer to plan their own trips and information technology (IT) is playing an increasingly important role in the hotel and tourism industry. Travel 
planning as a specific type of information search process for tourists, using IT, can be considered one of the central behavioural aspects of travel. To plan a trip, most tourists turn to intermediaries: travel agencies or online booking platforms. To provide quality services, these intermediaries use IT as a tool to support the tourist's decisions. Physical and online travel agencies use the services of global distribution system (GDS) providers to make the necessary reservations.

To advance in the future in terms of tourism, travel, and hospitality in the COVID-19 era, changes in the structure of tourist intermediation are foreseen, such as the modification of the roles of different intermediaries: tour operators, online travel agencies, own-web distribution, business-to-business and business-to-consumer, and the definitive dominance of digital intermediation (Chang et al., 2020b).

In the literature there are studies regarding research in technology in areas of tourism and hospitality, and also in tourism and hospitality management, but the strategic managerial approach and the involvement of IT and GDSs to provide solutions for the tourism industry in the current pandemic context are still being studied.

The aim of the paper is to provide solutions for the tourism industry in the current context of the COVID-19 pandemic, by involving IT and GDSs in the planning and booking process, as a decision supporting tool for tourists.

\section{Literature Review}

The widespread adoption of new technologies in tourism and hospitality industry in recent years has fundamentally reshaped the way services are provided and received (Kansakar et al., 2019). Tourism is constantly undergoing radical and, at the same time, rapid changes in terms of technology. Thus, the success of a business in the tourism industry has become dependent on digitalisation, with the final result of streamlining the business. Technological developments have led to an unprecedented revolution in the hospitality and tourism industry (Law et al., 2014). The tourism and hospitality industries have widely adopted IT to reduce costs, to increase operational efficiency, but also to improve the quality of services and the customer experience (Law et al., 2009). In this context, the understanding of technology-enhanced tourism experiences is very important (Neuhofer et al., 2014). Travel and tourism can be considered a critical field of testing and application for informatics, which, in turn, allows new services, prod- ucts, and cooperation in the tourism industry (Neidhardt \& Werthner, 2018).

IT is used in most sectors of the tourism industry and strongly influences the relations between producers and consumers, by shortening the distance between producer and customer, by identifying and satisfying the immediate requirements of consumers, and by introducing the possibility of innovation in attracting potential customers. Technological innovations bring together the full range of stakeholders in tourism service ecosystems, and technologically capable tourism experiences offer tourists the opportunity to create value at all stages of the journey (Buhalis, 2020). In the literature, we find many studies that have addressed various aspects of the implications and impact of information and communications technology (ICT) in tourism and hospitality, both from the supplier's perspective, on e-strategic management, e-marketing, guest services, e-security, and web design and analysis, and also through the prism of the consumer's perspective, regarding information search, evaluation of alternatives, purchase decisions, post purchase behavior, and technology adoption. In this context, understanding technology-enhanced tourism experiences is very important (Neuhofer et al., 2014). With the involvement of ICT in the rapid evolution of tourism, innovation activity in tourism has increased substantially in intensity (Aldebert et al., 2011; Foris et al., 2019).

Regarding the development of IT for tourism and hospitality, the first stage began with an evolution of reservations, more precisely through the computer reservation system (CRS), in the early 1960s, called the era of data processing, followed by the era of management information systems, the era of systems strategic information, and the age of information networks (Pencarelli, 2019). GDSs have their origins in CRS, being, in fact, an evolution of them based on a series of alliances, mergers, and acquisitions between suppliers, which were made with the distribution of information between customers and intermediaries that allows transactions, mainly between airlines, hotels, car rental companies, and travel agencies. GDSs are global enterprises whose structure is based on the maximum use of the Internet, characterised by the speed of information provision, the fact that it does not consume space, and the efficiency brought to customers in making sales, reservations, and information. In the tourism and hospitality industry, GDS refers to a network system that connects multiple vendors of services (including airlines, hotels, car rental companies, cruises, events, and activities) with end consumers or travel agents, and allows them to handle direct bookings (Pan, 2015). GDS is based on the actual time of obtaining the information released by the 
service providers and directs the request made by the clients, directly or through the travel agency, to the computerised reservation system used by the providers. There are three major competitive GDSs in the world: Travelport, Amadeus, and Sabre. They are constantly looking for new solutions for the development of the tourism industry through the exchange of supplier-customer or supplierintermediary-customer information (Falko, 2016).

Online booking platforms have emerged as a solution to facilitate bookings, so the booking can be made directly by the customer, without the need for an intermediary. Online search has become an increasingly important tool in the travel and tourism industry and about two-thirds of online travel uses search engines for planning. Search engines, through their indexing, matching, and ranking technologies, control what information is available to consumers and how it is presented (Gelter, 2017). Many of these booking platforms have considered the usefulness of the mobile phone for the technologically inclined population. Thus, applications have been created that have a consumer-friendly interface and are very easy to use.

Given the latest developments in technology, there are all sorts of inventions that come to the aid of everyday businesses, which are based on the evolution of technology. New digital technologies (Internet of Things [IoT], virtual reality [VR], augmented reality [AR], artificial intelligence [AI], connectivity, Web 4.0) represent the technical platform that allows the convergence of the concepts of Tourism 4.0 and smart tourism, with content that overlaps in the context of the fourth industrial revolution (Pencarelli, 2019). Thus, the Industrial Revolution 4.0 in tourism is based on various inventions, among the most important being AI and IoT. AI technologies have redefined the hospitality industry (Ruel \& Njoku, 2020). AI technology has become an important engine for the development of modern tourism and has penetrated every facet of the tourism industry (Zhang \& Sun, 2019). AI provides automated, personalised, and intelligent travel services, allows travellers to learn about their behaviours, and provides a personalised experience. Therefore, new emerging technologies such as chat bots, VR, language translators, and more can be effectively applied in the tourism and hospitality industry (Samala et al., 2020).

IoT technology has a multifaceted impact on the tourism industry, along with the requirements for mobility and flexibility throughout the travel and accommodation experience (Verma \& Shukla, 2019). The adoption of IoT technologies redesigns and improves the performance of all major business processes in the field of hospitality and can also be very useful in the tourism sector (Car et al., 2019). The IoT system implies that every thing com- municates, every thing is detectable, and every thing interfaces (Pencarelli, 2019). IoT technology is the future, in which anything can be adjusted, controlled, or verified using technology. In the tourism industry, IoT technology involves the use of technical devices such as geolocation bracelets, mobile guide apps, ticket payment apps, VR technologies, and more (Natocheeva et al., 2020).

Therefore, innovation and technology can contribute to a sustainable growth of tourism, given that tourism has never been a factor of conflict, but a factor and a sign of peace and prosperity (Loureiro, 2019).

Today, the trend of creating a global functional process for the provision of tourism services, based on the international system of global distribution, which is becoming an engine for the world tourism industry (Falko, 2016), is increasingly foreshadowed.

Tour operators, travel agencies, travel bureaus, tour agencies, and bureaus of realization of tourist-excursion vouchers, as commercial enterprises, are under the influence of globalization processes, which determine the improvement of the tourist infrastructure (Shatskaya, 2018). These processes are accompanied by the creation of new types of tourism enterprises, such as GDSs, reservation platforms, and tourism clusters.

There are quite a few studies that address issues regarding the influence of GDS in the tourism and hospitality industry. Thus, the perspective of a GDS operator on trends and opportunities affecting the tourism industry was studied (Loureiro, 2018), including the transformation of traditional GDS to travel trade platforms (Loureiro, 2016), the development of IT for processing large volumes of information on Live Travel Space from Amadeus (Shpyrnya, 2019), and the feasibility of developing and implementing GDS tours into the product portfolio of tourism enterprises (Roskladka \& Vrona, 2019). The appearance of GDS booking systems has improved and accelerated the system of interaction between the provider and the consumer of travel services (Shatskaya, 2018).

GDSs should be considered not as distribution channels, but as facilitators, providing interconnectivity between travel providers and distributors (Buhalis \& Licata, 2002). Thus, it becomes important to understand the potential involvement of GDSs and how new technologies can help identify solutions in the tourism and hospitality industry to ensure guest and staff safety, but also increase trust among tourists that their safety and health will not be endangered during their trip or their stay in the accommodation units. In this sense, this study will also consider the investigation of solutions for the involvement of IT and GDS in actions to protect the health of tourists and inform them about measures to ensure their safety. 


\section{Methodology}

Strategic management methods and comparative analysis are used to formulate strategies, measures, and solutions to maintain the safety and health of tourists in the tourism and hospitality industry in the current pandemic context, using established models for analysing the external environment: PEST and Porter's Five Forces, concluding with a SWOT matrix. The macro environmental analysis takes into account the political, economic, sociological, and technological factors. In the external environment analysis, we include a comparative analysis of the most important GDSs in the world-Travelport, Amadeus, and Sabreusing the data and information present on their sites and we will identify the set of analysis criteria. Regarding the comparative analysis, two features and 18 attributes have been identified, which have been grouped into a following set of analysis criteria. Specific features are (1) market share, (2) founding airlines, (3) portals, (4) airline solutions, (5) passenger name registration, (6) cars platform, (7) rail platform, (8) hospitality solutions, (9) travel agencies solutions, (10) optimization services, (11) central reservation system, (12) hotel property management system, (13) catering and sales, and (14) business-to-business (B2B). Technological features are (15) new digital technologies, (16) mobile, (17) data solutions, and (18) platform services. Microenvironment analysis focuses on the following factors: competition in the industry, potential of new entrants into the industry, power of suppliers, power of customers, and threat of substitute products. Based on the conclusions summarized in the SWOT matrix, strategic proposals and strategic guidelines will be formulated that include possible measures and solutions for the tourism and the hospitality industry through new digital technologies and the involvement of GDSs.

\section{Results and Discussion}

To present the relevant information in a structured way, the results are presented in a logical sequence. The macro environmental analysis captures important aspects of the environment-technological, economic, and political-in accordance with the factors related to regional mentalities, or sociological ones.

Regarding the political-economic factors, in this period of global pandemic crisis, the antagonistic tendencies between the globalization phenomena and the centralist, nationalist ones are evident. The phenomena are more pronounced at the level of the European Union
(EU) where states have adopted protection policies especially for their own citizens and have applied economic policies to protect their own business environment versus community policies. Euro-skeptical centrifugal trends are observed mainly in Italy, Spain, Portugal, Greece, Hungary, and Poland and in the United Kingdom after the Brexit period. At the U.S. level, the phenomenon was more pronounced during the 2020 presidential election campaign through the conflict between global democrats who support Joe Biden and Donald Trump's nationalist conservatives. Generally, Democrats were supporters of the lockdown followed by continued expansionist policies, where as many Republicans were supporters of freedom of movement within the federal union and focused on U.S. domestic needs.

All these had major influences on the tourism and hospitality industry. Some states remained open to tourists with certain restrictions (COVID-19 tests), and others were completely closed. Thus, Italy, Spain, France, Greece, and Portugal, countries with a major contribution of tourism to gross domestic product, have encouraged tourism to minimize losses. Others such as Hungary, Poland, and Romania have closed a large part of the public catering units as well as the spa and wellness centres, the consequences materializing in numerous bankruptcies of the economic agents and the migration, largely irreversible, of the labor force to other economic sectors or to other countries. Isolation trends with disastrous effects on tourism and hospitality have also manifested themselves in the Far East, Africa, and Latin America. Turkey was less affected due to the specifics of tourism units in the area-isolated resorts and clubs, on large areas of land, which allowed the strict application of preventive safety measures.

We can therefore conclude that globalization acts as a pressure factor on local tourism characterized by strong seasonal phenomena. In this context, to create a global functional process for the provision of tourism services, within the international system of global distribution, GDSs can become a locomotive for the world tourism industry. The most important GDSs in the world are Travelport, Amadeus, and Sabre. Travelport operates as a GDS with the help of three top brands: Worldspan, Galileo, and Apollo. It deals mainly with real-time ticket booking, but also with booking of accommodations, rental car services and other products. It also offers technologies, payments, distribution systems, and other operations for the global system (Travelport, 2020). Amadeus provides booking services, search services, ticketing, and many other realtime processing solutions, necessary for both suppliers in the tourism industry and travel agencies (Amadeus, 2020). Sabre is a provider of technological solutions in 
the tourism industry, offering customers in the field of air transport, hotels, and travel agencies the opportunity to develop their business (Sabre, 2020).

The potential for the involvement of GDSs as facilitators of interconnectivity between travel providers and distributors results from the comparative analysis of the three major players: Travelport (2020), Amadeus (2020), and Sabre (2020), made in terms of specific features.

1. Market share. These companies are distributed around the globe in such a way that they can maintain their market position. Travelport is present in Europe, Asia, Africa, and the Middle East; Amadeus is present all over the world, except in the United States, and Sabre is used in the United States and North America. There is fierce competition between Travelport and Amadeus due to continued expansion, but Sabre has stability in North America and the United States.

2. Founding airlines. For Travelport, founding airlines were Delta, British Airlines, KLM, SwissAir, and Alitalia (Worldspan + Galileo). For Amadeus, they were Lufthansa, Air France, Iberia, Continental Air, and Scandinavian. Sabre was founded on American, Australian, and JAL.

3. Portals. Travelport offers several portals: View My Trip, My Trip, and many others. Amadeus uses Check my Trip, and Sabre offers the Virtually There portal.

4. Airline solutions. Sabre was the first company to introduce passenger reservation, revenue or travel management systems for consumers, a corporate booking tool, and low-cost search systems in the tourism industry market. It offers the airline industry future-oriented IT solutions, from favourable applications to software-as-a-service (SaaS)-type systems that come to the aid of airlines. Travelport has the Airlines platform, an air commerce platform designed to manage the business in the field. Amadeus has a central reservation system, Amadeus CRS.

5. Passenger name registration. Travelport and Amadeus use alphanumeric language, and Sabre, serving a smaller area, uses only alphabetical language.

6. Cars platform. Travelport has the Cars platform, with an inventory base that allows rental car and mobility service providers to expose their offers through distribution channels.

7. Rail platform. Travelport has the Rail platform, which helps railway providers in exposing offers and information, but also in optimizing ticket sales with the help of travel agencies that receive this information in real time.

8. Hospitality solutions. Sabre offers three solutions of major importance in the hotel industry. The SynXis platform allows hoteliers to see the entire business; the optimization of data distribution offers tools for converting and searching for the best variants of distribution channels and obtaining low tariffs; and more precisely digital marketing promotions. Amadeus offers five products. Amadeus GDS Optimization targets the right selection of consumers in the market and helps manage marketing elements; Amadeus Hotel Reports helps to optimize investments; Amadeus Instant Preference makes it possible for the partner accommodation to appear as one of the first options for travel agencies at the time of booking; Distribution Solution connects to thousands of travel agencies; and Representation Solution, which can increase the number of bookings of the unit by collaborating with multiple travel agencies. Travelport offers the Hotels platform that connects travel agents and corporate travellers with the hotel system, helping the business in promoting and branding content through distribution channels.

9. Travel agencies solutions. Travelport offers two solutions. Retail Travel Agencies offers the possibility to meet customer requirements in a flexible, personal, and fast way. Online Travel Agencies (OTA) is a solution specially designed for personalization to increase conversion and reach new markets.

10. Optimization services. Travelport offers two solutions. Travel Management Company (TMC) is a solution designed for companies, to enable them to lead to customer satisfaction, optimize operational performance, and use new revenue opportunities. Corporations is a solution that continuously optimizes corporate travel, in ways beneficial to all participants, containing streamlined workflows, smart demandbased information, and cost optimization. Moreover, it has developed a solution for optimizing distribution capacity, New Distribution Capability (NDC), which addresses both airlines or travel agencies and the customer directly, helping them to manage or purchase travel more efficiently. Amadeus offers three solutions: Amadeus HotSOS Mild, a real-time information generator, designed for the hotel industry, which provides personalized services to customers; Amadeus Service Optimization HotSOS, an enterprise product, based on inventory; and HotSOS Housekeeping, a 
program to automate the cleaning system of hotels. Sabre uses the Online Commerce platform, which contains six optimization solutions. Sabre Travel Marketplace connects multiple sellers and buyers in the tourism industry through a platform. Sabre Red App Center allows travel agents to purchase and request applications needed to expand their workspace; Business trips and meetings can be booked through the GetThere platform, available on desktop, notebook, tablet, and smartphone. SynXis Central Reservation is a centre for booking reservations and researching rates and availability of accommodation. SynXis Booking Engine is a search engine with an intelligent reservation and personalization system. Airline Retailing provides airlines with the tools to increase revenue. Finally, SabreSonic Customer Sales \& Service helps airlines manage reservations, inventory control, and passenger check-in.

11. Central reservation system. This feature is provided only by Amadeus, which has Amadeus CRS, a single complete database that allows real-time viewing of the entire activity.

12. Hotel property management system. Amadeus provides a Property Management System (PMS) solution with fast deployments, low total cost of ownership, and maximum efficiency. Sabre has a PMS that allows owners to manage their business through an SaaS software system.

13. Catering and sales. Amadeus offers five products. Amadeus DirectBook allows planners to book meetings and events for small groups online. Amadeus Hospitality Diagramming Venue Edition allows for quick and easy organization of business room plans. Amadeus Hospitality Diagramming Website Edition offers plans, maps for areas, photos, virtual tours, camera charts, and even interactive camera settings, all available via computer or tablet. Amadeus MeetingBroker allows meeting planners to send event requests to the beneficiary's website directly through online distribution channels. Amadeus Sales \& Event Management offers solutions for sales and event management to streamline the beneficiary's business.

14. B2B solutions. Sabre offers Travel Network, a marketplace for B2B solutions, used by tourism industry suppliers, airlines, rail carriers, rental car companies, cruise lines, tour operators, and hotel properties to promote, customize, and sell their products to various intermediaries or customers. Travelport uses Blockchain, which allows travel agencies, service providers in the tourism industry, and also customers to receive and transmit data in real time.

The technological factors targeted in this study are those related to the implementation of new technologies and the involvement of GDSs as providers of technological solutions in the tourism industry. The potential of GDS involvement is shown as a result of the comparative analysis of the three major GDSs: Travelport (2020), Amadeus (2020) and Sabre (2020), made in terms of technological features.

15. New digital technologies. Travelport has developed an AI-based Technology and Innovation platform that includes global travel data. This is a digital infrastructure suitable for travel agencies to obtain maximum satisfaction of customer needs, through any means of contact (desktop, smartphone, tablet, notebook, etc) and to transmit real-time information as required. Moreover, Travelport developed Connectivity, an inventory of information about hotels, flights, reservations, and any information needed for the normal course of a trip. Sabre has developed three software solutions: Sabre Red Workspace, which allows travel agents to offer tourists differentiated experiences; Flight Management Solution Family, a solution that simplifies the management and dynamic changes involved in flight planning and monitoring; and Network Planning and Scheduling Solution Family, which gives airlines the ability to forecast demand and provide feasible and cost-effective programs.

16. Mobile. Travelport uses the Mobile theme and offers applications for hotel or airline reservations, but also for business monitoring, both in the case of travel agencies and hoteliers. Travelport Universal API allows tourism industry suppliers access to the online commerce platform, and Travelport Smartpoint SKD helps broaden business horizons and improve its workflows. Sabre offers four solutions for business management, by mobile phone: TripCase, a system that transmits information to tourists about travel, free of charge and in real time; Sabre Red Mobile Workspace, created especially for travel agencies, to be able to manage reservations and guide their clients; SynXis Booking Engine, which allows tourists to make reservations including from their mobile phone; and eFlight Manager, a system that supports the communication connections between the airlines and the control crew or the one on board, thus avoiding delays, due to the nearly instantaneous exchange of information. 
17. Data solutions. Sabre has developed four products. Sabre Traveler Security is an innovation that allows tourism managers to instantly identify travel locations and contact information. RezTrack is a tool for monitoring digital marketing programs by tracking performance indicators on hotel websites and the booking engine. Intelligence Exchange is a platform aimed at providing a complete real-time view of data and data analysis. SynXis Central Reservations provides hotel managers with real-time reports to help them manage their business both internally and externally.

18. Platform services. Sabre is based on two products: Sabre Dev Studio, which includes a range of tools for tourism industry developers, including information APIs, software developer kits, notification services, documentation and more; and SabreSonic Access, which offers the possibility for an airline to use its website as a real service channel, with flexibility and efficiency in use.

Technology is the basis of solutions to combat COVID19 and reopen tourism and the economy, offering various solutions: mobility tracing apps, robotised-AI touchless service delivery, digital health passports and identity controls, social distancing and crowding control technologies, big data for fast and real-time decision making, humanoid robots delivering materials, disinfecting and sterilizing public spaces, detecting or measuring body temperature, and providing safety or security (Sigala, 2020).

Sociological factors are analysed in terms of cultural characteristics that allow the study and definition of specific local or regional patterns of behaviour, consumption, and communication. At the level of the EU, all the progress made in recent years in terms of cultural differences through the policy of capitalizing on them under the slogan 'Unity through Diversity' seems to be fading, accentuating in this period of crisis local cultural differences of all kinds, in everyone's attempt to protect themselves first. Although the basic principle of the EU is that of unity, there is currently a phenomenon of stratification on four levels: the first level, globalist, of influence of Germany and France; the second nationalist of influence of Italy, Spain, and Portugal; the third, also nationalist, which includes the Visegrad countries-Hungary, Poland, the Czech Republic, and Slovakia; and the fourth, globalist, which includes Romania, Bulgaria, Greece, Estonia, Latvia, and Lithuania.

Likewise, the phenomenon is manifesting itself more and more globally, communities isolating themselves to protect themselves, with unfavourable effects on the movement of individuals, goods, and funds. In this process, the tourism and hospitality industry experienced the most dramatic declines along with related industries, especially transport. To all this was added the extreme weather phenomena throughout the United States, Western Europe, and Greece, as well as the drought in Eastern Europe, which foreshadows a food crisis.

Microenvironment analysis reveals the following.

1. Competition in the industry. At the industry level, global and European competition is particularly strong, with trends of market monopolization in certain segments.

2. Potential of new entrants into the industry. The entry of new competitors is difficult due to the particularly high costs and pressure of existing GDSs, which have invested huge amounts in development and promotion, having strong business relationships with all actors involved in the tourism and hospitality industry.

3 and 4. Power of suppliers and power of customers. It is relatively difficult to make a clear demarcation of GDSs' business relationships with economic operators, the latter being both customers and suppliers. The differentiation is made only in the case of final customers. Their bargaining power is almost insignificant compared to the huge economic power of GDSs.

5. Threat of substitute products. The threat of substitute products is insignificant, if we identify them only as tourist products sold directly or those created independently by tourists.

We summarize the conclusions of the external and internal environmental analyses through the SWOT matrix (Table 1) for the tourism and hospitality industry.

We formulate strategic proposals based on the conclusions summarized in the SWOT matrix.

\subsection{S-0 Strategy}

- Implementation of modern technologies and new digital technologies (IoT, AI, connectivity, Web 4.0, etc.) at the level of the tourism and hospitality industry.

- Increasing the involvement of GDSs in facilitating interconnectivity between the tourism service providers and suppliers and also in providing technological solutions to improve health security measures. 
Table 1: SWOT matrix

\begin{tabular}{|c|c|}
\hline $\begin{array}{l}\text { S } \\
\text { - The interest of the providers and suppliers of tourist services } \\
\text { regarding the implementation of sanitary safety measures } \\
\text {-Availability of tourism service suppliers and providers to identify } \\
\text { solutions to revive their business } \\
\text { - The existing relationship between GDSs, providers, and suppliers } \\
\text { of tourist services } \\
\text { - The existing relationship between the modern digital technology } \\
\text { providers and the suppliers and providers of touristic services }\end{array}$ & $\begin{array}{l}\text { W } \\
\text { - The perception of the staff at the level of the providers and suppli- } \\
\text { ers of tourist services that they can get sick during the professional } \\
\text { activities and the decrease of their involvement in the provision of } \\
\text { services } \\
\text {-The bankruptcy of some providers and suppliers of tourist services } \\
\text { - Insufficiency of the necessary funds for investments at the level of } \\
\text { providers and suppliers of tourist services }\end{array}$ \\
\hline $\begin{array}{l}\text { - The existence of modern technologies with applicability for } \\
\text { tourism } \\
\text { - The solutions offered by the new digital technologies for the } \\
\text { improvement of tourism services } \\
\text {-Diversity of solutions developed by GDSs for business develop- } \\
\text { ment, interconnectivity, and new technologies for the tourism and } \\
\text { hospitality industry } \\
\text {-Globalized capacity to provide new digital technologies and GDS } \\
\text { services }\end{array}$ & $\begin{array}{l}\text { T } \\
\text { - Current pandemic situation } \\
\text { - Tourists' distrust regarding their safety and health during the trip } \\
\text { or during their stay } \\
\text { - Incoherent and inappropriate actions and measures at the level of } \\
\text { governments regarding the protection of the tourism and hospital- } \\
\text { ity industry } \\
\text {-The global crisis generated by the COVID-19 pandemic }\end{array}$ \\
\hline
\end{tabular}

- Increasing the involvement of GDSs in facilitating interconnectivity between the tourism service providers and suppliers and also in providing technological solutions for improving the communication with tourists.

\subsection{W-0 Strategy}

- Involvement of new digital technologies and GDSs in the action of guest and staff safety.

- The involvement of the digital technologies and the GDSs in the improvement of tourism services.

- Using improved solutions of GDSs for business development for the providers and suppliers of tourism services.

\subsection{S-T Strategy}

- Proper management of the pandemic situation at governmental level, through measures that do not affect, more than is absolutely necessary, the business of the hospitality and tourism industry.

- Creating financing programs for investments in new technologies that can be accessed by providers of tourist services.

- The involvement of new digital technologies and GDSs in the action of reestablishing trust among tourists that their safety and health during the trip or during the stay are not endangered.

\subsection{W-T Strategy}

- Coherent and appropriate actions and measures at the level of governments regarding the protection of the tourism and hospitality industry and the support of the companies affected by the crisis.

- Elaboration of cleaning and disinfection standards at the governmental level, their implementation at the level of the tourism and hospitality industry, and their promotion at the level of society.

- Elaboration of behavioural protocols of the staff but also of the tourists, specific to each type of activity in the field of tourism, their implementation, and their promotion at the level of the population.

The following are strategic guidelines that include possible measures and solutions for the tourism and the hospitality industry through new digital technologies and the involvement of GDSs:

- Implementation of new digital technologies offers solutions for the tourism industry to weather the current pandemic situation. The use of AI technology leads to improved services for tourists, and the use of chat bots (integrated into customer relations systems at hotels, airlines, locations, or tourist attractions) to instantly answer questions from tourists but also 
to provide detailed information on the implemented sanitary measures represent possible solutions to increase tourists' confidence regarding their safety. Moreover, in hotel rooms, voice control technology can be introduced, through Alexa-type applications that will allow tourists to avoid contact with surfaces.

- Travel service providers can focus on the personalisation trend, which comes to the aid of tourists who want a lot of information and recommendations, made and transmitted by AI, both when researching the destination and booking, and then again during their stay. Thus, AI can generate a tourist package based on information previously entered in a questionnaire by the tourist. Implementing IoT in the tourism industry is a solution through which anything can be adjusted, controlled, or verified using technology. This technology can be used to help prevent tourists from touching surfaces in hotels, which will allow access to the elevator, entry into rooms, and adjustment of settings such as humidity or temperature, TV use, and more, with the help of this technology installed on the tourist's phone or tablet. The use of humanoid robots in hotels to provide information at the request of tourists is also a useful solution. Regarding the use of AI technology during a trip, we find it in the form of realtime flight notifications, information received on the phone or tablet regarding boarding gates or security information. Also, during flights, sensors can be integrated in passenger seats that can monitor the pulse, anxiety level, dehydration, and temperature of their bodies.

- Involvement of GDSs as facilitators of interconnectivity between travel providers and distributors and use of solutions offered by the three main GDSs: portals, hospitality solutions, travel agency solutions, optimization services, CRS offered by Amadeus, PMS hotels, catering and sales, B2B solutions, and transport solutions, including airline solutions, but also the Cars platform and Rail platform offered by Travelport.

- Involvement of GDSs as providers of technological solutions and use of the solutions offered by the three GDSs: new digital technologies, mobile applications, data solutions, and platform services.

\section{Conclusions}

There is a real potential for the involvement of GDSs as facilitators of the interconnectivity between travel providers and the distributors as well as the providers of techno- logical solutions, all of which are likely to offer solutions both in terms of returning to normality of the hospitality and tourism industry, but also regarding the actions of protection and information of tourists regarding the sanitary safety and sanitation measures implemented by the providers, right from the moment of planning the trip. The technology is a foundation on which solutions can be built and identified to combat COVID-19 and reopen travel and tourism, and the implementation of new digital technologies such as AI, IoT, connectivity, Web 4.0, and so on, in actions to protect tourists' health and communication are a huge step in rebuilding the confidence of tourists that their safety and health will not be endangered during a trip or during their stay in an accommodation unit. Moreover, it is necessary to promote cleaning and disinfection programs so that people know what tourism service providers are doing, but also behavioural protocols, so that tourists know what to do and how the staff of tourism service providers should behave, as well as the promotion of available technologies for ensuring the protection of tourists.

The results of the study are useful for small and medium enterprises to organize at a professional level, to develop better communication, to act efficiently, and to prevent the contamination of tourists with the COVID-19 virus in their units. The results help GDS providers reflect on possible improvements to the system's functionality to implement solutions that support tourists' decisions in the current pandemic context.

From an academic point of view, this research helps to consolidate existing studies on the strategic managerial approach and by involving technology and GDSs in providing innovative solutions to the tourism industry, which are necessary in the current pandemic context.

This study is a small step forward in identifying solutions for the tourism industry in the current context of the COVID-19 pandemic. The study is a potential strategic guide for small and medium-sized enterprises to use IT and GDSs to cross the current pandemic context. This study still presents some limitations. The results of this study are general guidelines that could be adopted and not concrete strategies to be followed by most small and medium-sized companies. Future research could be expanded to complement this study by including studies focused on identifying specific, concrete strategies for types of activities in the tourism industry in the areas of accommodation, food, transport, and leisure. 


\section{Bionotes}

Diana Foris is an associate professor on the faculty of Food and Tourism, Transilvania University of Brasov, Romania. Since joining the Transilvania University, she has been involved with studies related to hospitality and tourism management. Author of eight books and more than 60 articles published in scientific journals and international conference proceedings, she is an integrated member of the Centre for Tourism Research, Development and Innovation, Portugal. Before joining Transilvania University, she worked for the Romanian Ministry of Tourism as a counselor and in projects on tourism and food personnel qualification and specialization grants for the EU, funded as team leader, expert, and lecturer.

Cristina-Alexandra Matei is currently an MSc postgraduate student at the Anglia Ruskin University Cambridge Campus, United Kingdom, and a graduate from Transilvania University of Brasov, Faculty of Food and Tourism, Romania. During her studies, she took part in international mobility projects related to hospitality and tourism. She is interested in tourism and hospitality technologies, science-marketing, and graphic design.

Tiberiu Foris is a professor and the head of the Department of Management and Economic Computer Science, Transilvania University of Brasov, Romania. He is the manager of the School of Tourism Managerial Training and of the Central Region industry owners' union UGIR-1903, a member of INFER Koln, Germany, and an integrated member of the Centre for Tourism Research, Development and Innovation, Portugal. He was the manager of strategic projects for vocational training in tourism, food industry, printing, and massmedia. He has published numerous books and scientific papers in the field of management and five books of poetry.

\section{References}

[1] Aldebert, B., Dang, R.J.,\& Longhi, C. (2011). Innovation in the tourism industry: The case of Tourism@.Tourism Management, 32(5), 1204-1213.

[2] Amadeus. (2020). Home page.https://amadeus.com/en

[3] Buhalis, D. (2020). Technology in tourism-From information communication technologies to eTourism and smart tourism towards ambient intelligence tourism: Aperspective article. Tourism Review, 75(1), 267-272.

[4] Buhalis, D.,\& Licata, M. C. (2002). The future eTourism intermediaries. Tourism Management, 23(3), 207-220.

[5] Car, T., Pilepić-Stifanich, L.,\& Šimunić, M. (2019). Internet of Things (IoT) in tourism and hospitality: Opportunities and
challenges.ToSEE: Tourism in Southern and Eastern Europe, 5, 163-175.

[6] Chandrasekaran, K.S.,\& Dhanalakshmi, N. (2020). The pandemic effect on the tourism industry. Strad Research, 7(9), 33-39.

[7] Chang, C.-L., McAleer, M.,\& Ramos V. (2020a). A charter for sustainable tourism after COVID19. Sustainability, 12(9:3671), 1-4.

[8] Chang, C.-L., McAleer, M.,\& Ramos V. (2020b). The future of tourism in the COVID-19 era. Advances in Decision Sciences,24(3), 218-230.

[9] Falko, E. (2016). Analysis of the global distribution systems on the international market of tourist services. European Journal of Management Issues, 24(6), 15-22.

[10] Foris, D., Tecau, A.S., Hartescu, M.,\& Foris, T. (2019). Relevance of the features regarding the performance of booking websites. Tourism Economics, 26(6), 1021-1041.

[11] Gelter, H. (2017). Digital tourism: An analysis of digital trends in tourism and customer digital mobile behaviour. Interreg Nord.https://www.mynewsdesk.com/se/outdoormap/ documents/digital-tourism-an-analysis-of-digital-trends-intourism-and-customer-digital-mobile-behaviour-for-the-visitarctic-europe-project-67782

[12] Gössling, S., Scott, D., \& Hall, C. M. (2020). Pandemics, tourism and global change: a rapid assessment of COVID-19. Journal of Sustainable Tourism, 29(1), 1-20. https://doi. org/10.1080/09669582.2020.1758708

[13] Gretzel, U., Fuchs, M., Baggio, R., Hoepken, W., Law, R., Neidhardt, J., Pesonen, J., Zanker, M., \& Xiang, Z. (2020). e-Tourism beyond COVID-19: Acall for transformative research. Information Technology \& Tourism, 22, 187-203.

[14] Hall, C.M., Scott, D.,\& Gössling, S. (2020). Pandemics, transformations and tourism: Be careful what you wish for. Tourism Geographies. https://www.tandfonline.com/doi/ full/10.1080/14616688.2020.1759131

[15] Jamal, T. and Budke, C. (2020), "Tourism in a world with pandemics: local-global responsibility and action”, Journal of Tourism Futures, Vol. 6 No. 2, pp. 181-188. https://doi. org/10.1108/JTF-02-2020-0014

[16] Kansakar, P., Munir, A.,\& Shabani, N. (2019). Technology in the hospitality industry: Prospects and challenges. IEEE Consumer Electronics Magazine, 8(3), 60-65.

[17] Khan, S. (2020). COVID 19: Tourism at crossroads! What next? Journal on Tourism \& Sustainability, 3(2), 32-40.

[18] Kock, F., Norfelt, A., Josiassen, A., Assaf, A.G.,\& Tsionas, E. M.(2020). Understanding the COVID-19 tourist psyche: The evolutionary tourism paradigm. Annals of Tourism Research, 85, 103053.

[19] Kumar, U. (2020, May). The economic and psychological impact of SARS-Cov2 on travel and tourism industry: With special reference to India. Online International Interdisciplinary Conference on Our Earth Our Resources.https://www. researchgate.net/publication/341804662_Covid-[19]_and Tourism_Industry?channel=doi\&linkId=5ed579d7299bf$1 \mathrm{c} 67 \mathrm{~d} 326119$ \&showFulltext $=$ true

[20] Law, R., Buhalis, D.,\&Cobanoglu, C. (2014). Progress on information and communication technologies in hospitality and tourism. International Journal of Contemporary Hospitality Management, 26(5), 727-750. 
[21] Law, R., Leung, R.,\& Buhalis, D. (2009). Information technology applications in hospitality and tourism: Areview of publications from 2005 to 2007. Journal of Travel \& Tourism Marketing, 26(5-6), 599-623.

[22] Loureiro, A. (2016). Redefining travel commerce: The Travelport perspective. Worldwide Hospitality and Tourism Themes, 8(6), 699-704.

[23] Loureiro, A. (2018). There is a fourth industrial revolution: The digital revolution. Worldwide Hospitality and Tourism Themes, 10(6), 740-744.

[24] Loureiro, A. (2019). Innovation and technology-The only answer for sustainable tourism growth. Worldwide Hospitality and Tourism Themes, 11(6), 743-747.

[25] Natocheeva, N., Shayakhmetova, L., Bekkhozhaeva, A., Khamikhan, N.,\& Pshembayeva, D. (2020). Digital technologies as a driver for the development of the tourism industry. E3S Web of Conferences, 159(1), 04002. https://www.researchgate.net/ publication/340124453_Digital_Technologies_as_a_Driver_ for_the_Development_of_The_Tourism_Industry

[26] Neidhardt, J.,\& Werthner, H. (2018). IT and tourism: Still a hot topic, but do not forget IT. Information Technology \& Tourism, 20, 1-7.

[27] Neuhofer, B., Buhalis, D.,\& Ladkin, A. (2014). A typology of technology-enhanced tourism experiences. International Journal of Tourism Research, 16(4), 340-350.

[28] Pencarelli, T. (2019). The digital revolution in the travel and tourism industry. Information Technology \& Tourism.https:// link.springer.com/article/10.1007\%2Fs40558-019-00160-3

[29] Roskladka, N.,\& Vrona, A. (2019). Gds-Tour as an optimization tool for the product portfolio of tourism enterprise. Problems of Systemic Approach in the Economy, 4(72), 100-106.

[30] Pan, B. (2015). Global distribution system. In Encyclopedia of tourism. Springer. https://www.researchgate.net/
publication/270273918_Global_Distribution_System?channel=doi\&linkId=54a427180cf267bdb906709a\&showFulltext=true

[31] Ruel, H. and Njoku, E. (2021), “Al redefining the hospitality industry”, Journal of Tourism Futures, Vol. 7 No. 1, pp. 53-66. https://doi.org/10.1108/JTF-03-2020-0032

[32] Sabre. (2020). Home page.https://www.sabre.com/insights/ labs/

[33] Samala, N., Katkam, B.S., Bellamkonda, R.S. and Rodriguez, R.V. (2020), "Impact of Al and robotics in the tourism sector: a critical insight", Journal of Tourism Futures, Vol. ahead-of-print No. ahead-of-print. https://doi.org/10.1108/ JTF-07-2019-0065

[34] Shatskaya, Z. (2018). Global enterprises in the tourist industry. Paradigm of Knowledge, 1(27), 1527. https:// naukajournal.org/index.php/Paradigm/article/ view/1439/1527

[35] Shpyrnya, O.V.(2019). Amadeus company's activity strategy in the market of tourist services. Scientific Bulletin of the Southern Institute of Management, 3, 100-104.

[36] Sigala, M. (2020). Tourism and COVID-19: Impacts and implications for advancing and resetting industry and research. Journal of Business Research, 117, 312-321.

[37] Travelport. (2020). Home page. https://www.travelport. com/\#Solutions

[38] Verma, A.,\& Shukla, V. (2019, Feburary 26-28). Analyzing the influence of IoT in tourism industry [Paper presentation]. International Conference on Sustainable Computing in Science, Technology and Management, Amity University, Rajasthan, Jaipur, India.https://papers.ssrn.com/sol3/ papers.cfm?abstract_id=3358168

[39] Zhang, L.,\& Sun, Z. (2019). The application of artificial intelligence technology in the tourism industry of Jinan. Journal of Physics, 1302(3), 032005. 